\title{
Mature BDNF promotes the growth of glioma cells in vitro
}

\author{
JING XIONG ${ }^{1,3}$, LI ZHOU ${ }^{1}$, YOON LIM ${ }^{2}$, MIAO YANG ${ }^{2}$, YU-HONG ZHU ${ }^{3}$, \\ ZHI-WEI LI ${ }^{3}$, FIONA H. ZHOU ${ }^{2}$, ZHI-CHENG XIAO ${ }^{1,4}$ and XIN-FU ZHOU ${ }^{1,2}$ \\ ${ }^{1}$ Key Laboratory of Stem Cells and Regenerative Medicine, Institute of Molecular and Clinical Medicine, \\ Kunming Medical University, Kunming, Yunnan, P.R. China; ${ }^{2}$ School of Pharmacy and Medical Sciences, \\ University of South Australia, Adelaide, SA 5000, Australia; ${ }^{3}$ The Second Hospital Affiliated to \\ Kunming Medical University, Kunming, Yunnan, P.R. China; ${ }^{4}$ Department of Anatomy and \\ Developmental Biology, Monash University, Clayton, VIC 3800, Australia
}

Received July 24, 2013; Accepted August 26, 2013

DOI: $10.3892 / o r .2013 .2746$

\begin{abstract}
High-grade glioma is incurable and is associated with a short survival time and a poor prognosis. There are two forms of brain-derived neurotrophic factor (BDNF), proBDNF and mature BDNF, which exert opposite effects. Their diverse actions are mediated through two different transmembrane receptor signalling systems: p75NTR and TrkB. The important roles of the BDNF/TrkB signalling system in tumour cell proliferation and survival have been demonstrated. However, few studies have been able to distinguish mature BDNF from proBDNF due to the limitation of specific antibodies. Using specific proBDNF antibodies, we demonstrated that the proBDNF/p75NTR pathway appears to inhibit malignant glioma cell growth and migration. In the present study using specific mature BDNF antibodies, we found that mature BDNF inhibited C6 glioma cell apoptosis and increased cell growth and migration in vitro. Our data suggest that the counterbalance between mature BDNF and proBDNF may regulate tumour growth.
\end{abstract}

\section{Introduction}

Brain-derived neurotrophic factor (BDNF), a member of the neurotrophin family, is known to regulate cell growth, differentiation, migration and apoptosis in the nervous system $(1,2)$. There are two forms of BDNF, a precursor and a mature form, in the central nervous system (CNS) (3). The precursor of BDNF (proBDNF) is synthesised and subsequently cleaved either intracellularly by prohormone convertases (PCs) and/

Correspondence to: Professor Xin-Fu Zhou, School of Pharmacy and Medical Sciences, University of South Australia, Adelaide, SA 5000, Australia

E-mail:xin-fu.zhou@unisa.edu.au

Professor Zhi-Cheng Xiao, Department of Anatomy and Developmental Biology, Monash University, Clayton, VIC 3800, Australia

E-mail: zhicheng.xiao@monash.edu

Key words: brain-derived neurotrophic factor, TrkB, C6 glioma cells or furin, or extracellularly by plasmin and matrix metalloproteases (MMPs) to release the mature homodimeric protein (mature BDNF) (4,5). Their diverse actions are mediated through two different transmembrane receptor signalling systems: Trk tyrosine kinase B (TrkB) receptor and p75 neurotrophin receptor (NTR). Mature BDNF activates the high affinity TrkB receptor, promoting cell survival while proBDNF binds to both p75NTR and the co-receptor sortilin with a high affinity, to modulate cell apoptosis (6-8).

Increasing evidence suggests that altered signalling through TrkB promotes tumour formation and metastasis. TrkB, in conjunction with its primary ligand BDNF, is often overexpressed in a variety of human cancers, ranging from neuroblastomas to pancreatic ductal adenocarcinomas, where it may allow tumour expansion and contribute to resistance to antitumour agents (9). Neurotrophin genes were found to be expressed in 24 cell lines derived from human malignant gliomas, and the $B D N F$ gene was most abundantly expressed (10). Expression of Trk receptors (TrkA, TrkB and $\operatorname{TrkC}$ ) has been detected in human astrocytomas and promotes tumour growth. Furthermore, activation of the JNK pathway may contribute to progression towards malignancy (11). Expression of BDNF and TrkB is also observed in human gangliogliomas (12). However, histological data in previous studies were unable to distinguish mature BDNF from proBDNF due to the lack of specific antibodies. We generated specific antibodies to mature BDNF and proBDNF, respectively. In our recent study, the proBDNF/p75NTR pathway appeared to inhibit malignant glioma cell growth and migration (13). A recent report also showed that proBDNF suppressed the growth of colorectal cancer cells (14). Therefore, we postulated that the mature form of BDNF plays a supportive role in the growth and migration of tumour cells. In the present study, specific anti-mature BDNF antibodies were used. We examined the role of mature BDNF in glioma using the C6 glioma cell line in vitro.

\section{Materials and methods}

C6 cell culture. C6 glioma cells were grown in low-glucose Dulbecco's modified Eagle's medium (DMEM; Gibco) 
supplemented with $10 \%$ fetal bovine serum (FBS; Gibco) or otherwise specified, $1 \%$ glutamate and $1 \%$ penicillin/streptomycin at $37^{\circ} \mathrm{C}$ in a humidified atmosphere of $5 \% \mathrm{CO}_{2}$ and $95 \%$ air.

Fluorescence double-labelling of mature BDNF and TrkB in C6 cells. C6 cells were cultured on coverslips and fixed with $4 \%$ paraformaldehyde in PBS at room temperature for 20 min. Co-expression of mature BDNF/TrkB was assayed by immunofluorescence double-labelling as previously described (13). After blocking, the sections were first incubated with sheep anti-mature BDNF ( $2 \mu \mathrm{g} / \mathrm{ml}$; laboratory of X.-F. Zhou) and rabbit anti-TrkB (1:1000; Millipore) at $4^{\circ} \mathrm{C}$ overnight, and then with donkey anti-goat Alexa 488 (green) $(1: 1,000)$ and anti-rabbit Alexa 546 (red) $(1: 1,000)$ (both from Invitrogen) secondary antibodies for $1 \mathrm{~h}$. The sections were mounted with mounting media containing 4',6'-diamidino-2-phenylindole (DAPI; Vector Laboratories) and observed and photographed using a Leica confocal microscope.

Western blot analysis. The C6 cells were harvested with lysis buffer containing $50 \mathrm{mM}$ Tris $\mathrm{HCl},(\mathrm{pH} 7.4), 150 \mathrm{mM} \mathrm{NaCl}$, $1 \%$ nonyl-phenoxylpolyethoxylethanol (NP)-40, $1 \%$ sodium deoxycholate, $0.1 \%$ sodium dodecyl sulfate (SDS) and protease inhibitor cocktail (Roche), vortexed and centrifuged at $4^{\circ} \mathrm{C}$ at $13,000 \mathrm{rpm}$ for $20 \mathrm{~min}$.

Western blot analysis was conducted as described in our previous report (13). In brief, after blocking, the membranes were incubated with sheep anti-mature BDNF $(2 \mu \mathrm{g} / \mathrm{ml})$ and rabbit anti-TrkB (1:1,000; Millipore) at $4^{\circ} \mathrm{C}$ overnight. After several washes in TBST, the membranes were incubated with HRP-conjugated secondary antibodies (mouse anti-goat or goat anti-rabbit, 1:1,000; both from Santa Cruz Biotechnology) for $2 \mathrm{~h}$ at room temperature. Immunoreactive bands were detected using an enhanced chemiluminescence kit (CWBio Technology).

Cell viability assay. The cell viability assay was conducted as previously described in detail (13). Cells were plated and treated with recombinant mature BDNF protein $(1,3,10$ and $30 \mathrm{ng} / \mathrm{ml})$ or anti-mature BDNF $(1,3$ and $10 \mu \mathrm{g} / \mathrm{ml})$ dissolved in serum-free media. The control remained untreated. The treated cells were incubated for 24-48 h. The 3-(4,5-dimethylthiazol-2-yl)-2, 5-diphenyltetrazolium bromide (MTT) (Sigma) assays were performed at 0,24 and $48 \mathrm{~h}$. To minimise the variation among different assays, the data were corrected against the control and were plotted using the optical density of the control wells as $100 \%$ survival. The experiments were performed in triplicate and repeated at least three times.

Cell apoptosis assay. C6 cells were plated (15,000/well) in 96-well plates and cultured to $60-70 \%$ confluency. On the day of the experiment, the cells were treated and prepared as above in serum-free medium. After $48 \mathrm{~h}, \mathrm{C} 6$ cells were fixed using 4\% paraformaldehyde for $20 \mathrm{~min}$ and then stained with DAPI as previously reported (15). Cell images were collected (at least five fields/well) using a fluorescence microscope (Leica) for each sample. The apoptotic and total number of nuclei were counted. The ratio of apoptotic nuclei was calculated against the total number of nuclei counted. To minimise the variation among different assays, the data were corrected against the control.

Scratch assay. The details of the scratch assay were previously described (13). Confluent monolayer cells were scratched with a 10- $\mu 1$ pipette tip, washed, photographed $(0 \mathrm{~h})$ and treated with recombinant mature BDNF protein $(1,3,10$ and $30 \mathrm{ng} / \mathrm{ml})$ or mature BDNF antibodies $(1,3$ and $10 \mu \mathrm{g} / \mathrm{ml})$. The cells were cultured in serum-free medium for another $24 \mathrm{~h}$ and were then photographed at the same position. The relative migration distance was calculated using the following formula: Relative migration distance $=(\mathrm{A}-\mathrm{B}) / \mathrm{A}$, where $\mathrm{A}$ represents the mean width of the cell scratch before treatments and $B$ represents the mean width of the cell scratch after treatments. Results are expressed as the means $\pm \mathrm{SE}$.

Cell invasion assay. C6 cell invasion was examined using 24-well Boyden chemotaxis chamber (BD Biosciences) as previously described (13). Cells ( $3 \times 10^{5} /$ well) were seeded into the upper compartment individually and incubated in $100 \mu \mathrm{l}$ serum-free media containing recombinant mature BDNF $(1$, $3,10$ and $30 \mathrm{ng} / \mathrm{ml})$ or antibodies to mature $\operatorname{BDNF}(1,3$ and $10 \mu \mathrm{g} / \mathrm{ml}$ ), while $750 \mu \mathrm{l} /$ well of media containing $20 \%$ FBS was placed in the bottom wells. Controls remained untreated. After a 24-h incubation at $37^{\circ} \mathrm{C}$ in a $\mathrm{CO}_{2}$ incubator, the cells on the upper surface of the inserts were gently wiped off with a cotton swab. The cells on the lower surface of the inserts were fixed, stained with DAPI and sampled. The data are presented as means \pm SE. In additional experiments, the cells on the bottom of the insert were stained with Cresyl violet solution $(0.2 \%)$ for $15 \mathrm{~min}$. The dye was extracted with $10 \%$ acetic acid, and dye levels were directly proportional to the number of cells (16). The absorbance was measured at $570 \mathrm{~nm}$ using an EIA microplate reader.

Statistical analysis. The data of the cell experiments from different groups were analysed by one-way analysis of variance (ANOVA) followed by post-hoc analysis of multiple comparisons. $\mathrm{P}<0.05$ was considered to indicate a statistically significant result.

\section{Results}

Expression of mature BDNF and its receptor TrkB in C6 cells. To examine the effect of mature BDNF, the C6 cell line was used in the present study. Immunostaining and western blots showed the expression of mature BDNF and its main receptor TrkB in C6 cells (Fig. 1). These results indicate that mature BDNF may activate its receptors by an autocrine mechanism in the behavior of $\mathrm{C} 6$ glioma cells.

Mature BDNF promotes $C 6$ cell growth. Next, we investigated whether mature BDNF promotes the growth of glioma cells. As shown in Fig. 2A and C, MTT assays revealed that exogenous mature BDNF significantly increased cell proliferation at a dose of $30 \mathrm{ng} / \mathrm{ml}$. Blocking endogenous mature BDNF by using mature BDNF antibodies inhibited cell proliferation in a dose-dependent manner (Fig. 2B and C), supporting the specific roles of endogenous mature BDNF signalling in promoting glioma cell growth. 

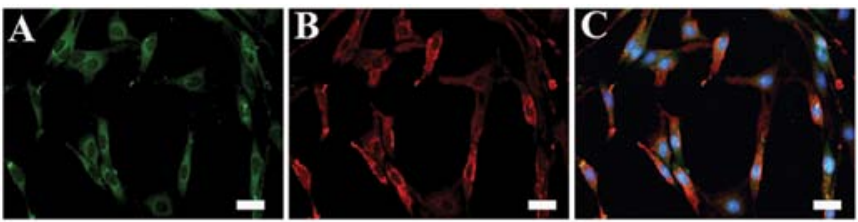

D

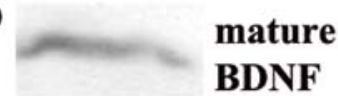

$\mathbf{E}$

Figure 1. Expression of mature BDNF and TrkB in C6 glioma cells (A-C) Fluorescence double-labelling of mature BDNF and TrkB in C6 cells: mature BDNF (green), TrkB (red), DAPI nuclear counterstaining (blue) yellow indicates the merged area. Scale bar, $25 \mu \mathrm{m}$. (D and E) Western blot analyses for mature BDNF and TrkB, respectively.
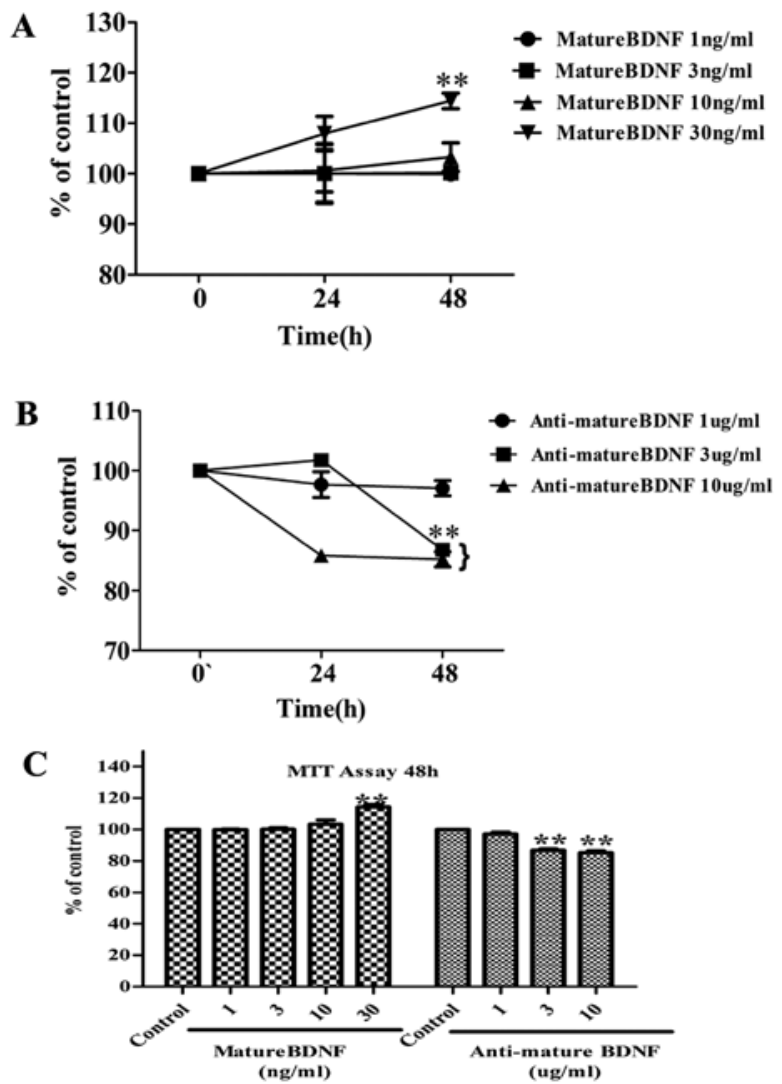

Figure 2. Growth of C6 cells following treatment with mature BDNF or anti-mature BDNF antibodies in serum-free medium. Cells were incubated in serum-free medium, supplemented with indicated concentrations of antimature BDNF antibodies $(1,3$ and $10 \mu \mathrm{g} / \mathrm{ml})$ or mature $\operatorname{BDNF}(1,3,10$ and $30 \mathrm{ng} / \mathrm{ml}$ ) in 96-well plates. MTT assays were performed after 0, 24 and $48 \mathrm{~h}$ for each treatment in triplicate. (A and C) Mature BDNF promoted C6 cell growth under a serum-free condition after $48 \mathrm{~h}$. (B and C) Anti-mature BDNF antibodies inhibited C6 cell survival after $48 \mathrm{~h}$. Data are presented as means \pm SE. Results were replicated in at least three independent experiments. Controls were set as $100 \%$. ${ }^{* *} \mathrm{P}<0.01$.

Mature BDNF inhibits apoptosis of C6 cells in vitro. To support the notion that mature BDNF promotes the growth of glioma cells, we further investigated whether this molecule is involved in protecting against apoptosis. Following the addition of antimature BDNF antibodies $(1,3$ and $10 \mu \mathrm{g} / \mathrm{ml})$ into the cultured C6 cells, the apoptosis of $\mathrm{C} 6$ cells was significantly promoted in a dose-dependent manner (Fig. 3A, B and D). In contrast,
A

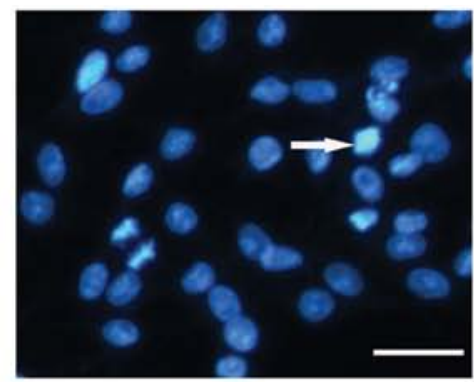

B

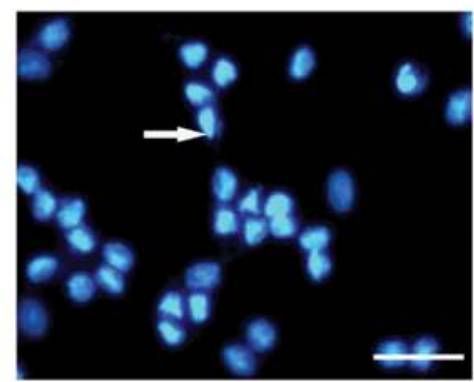

C

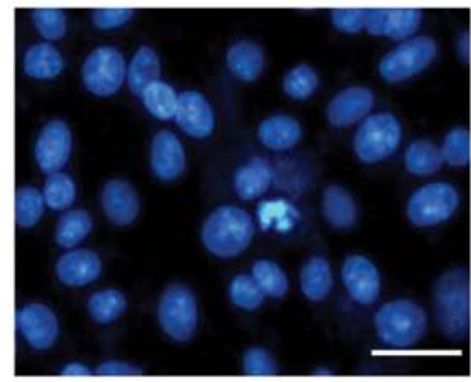

D

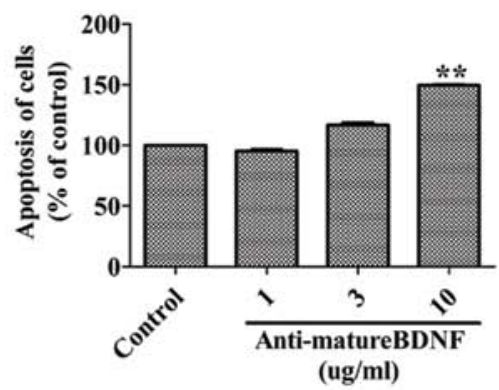

$\mathbf{E}$

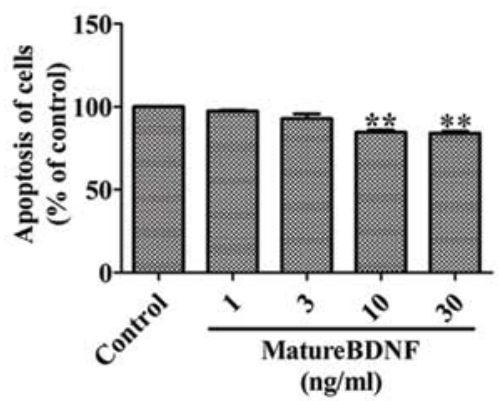

Figure 3. Effects of mature BDNF antiserum and recombinant mature BDNF on cell death of $\mathrm{C} 6$ cells cultured in serum-free medium. (A) Control. (B) Anti-mature BDNF treatment $(10 \mu \mathrm{g} / \mathrm{ml})$. (C) Recombinant mature BDNF treatment $(30 \mathrm{ng} / \mathrm{ml})$. Arrowheads indicate representative apoptosis cells. Scale bar, $25 \mu \mathrm{m}$. (D) Quantitive analysis of apoptosis in C6 cells following treatment with anti-mature BDNF at different concentrations. (E) Quantitive analysis of apoptosis of C6 cells following treatment with recombinant mature BDNF at different concentrations. DAPI data are expressed as the percentage of the control. Results were replicated in at least three independent experiments. ${ }^{* *} \mathrm{P}<0.01$ 

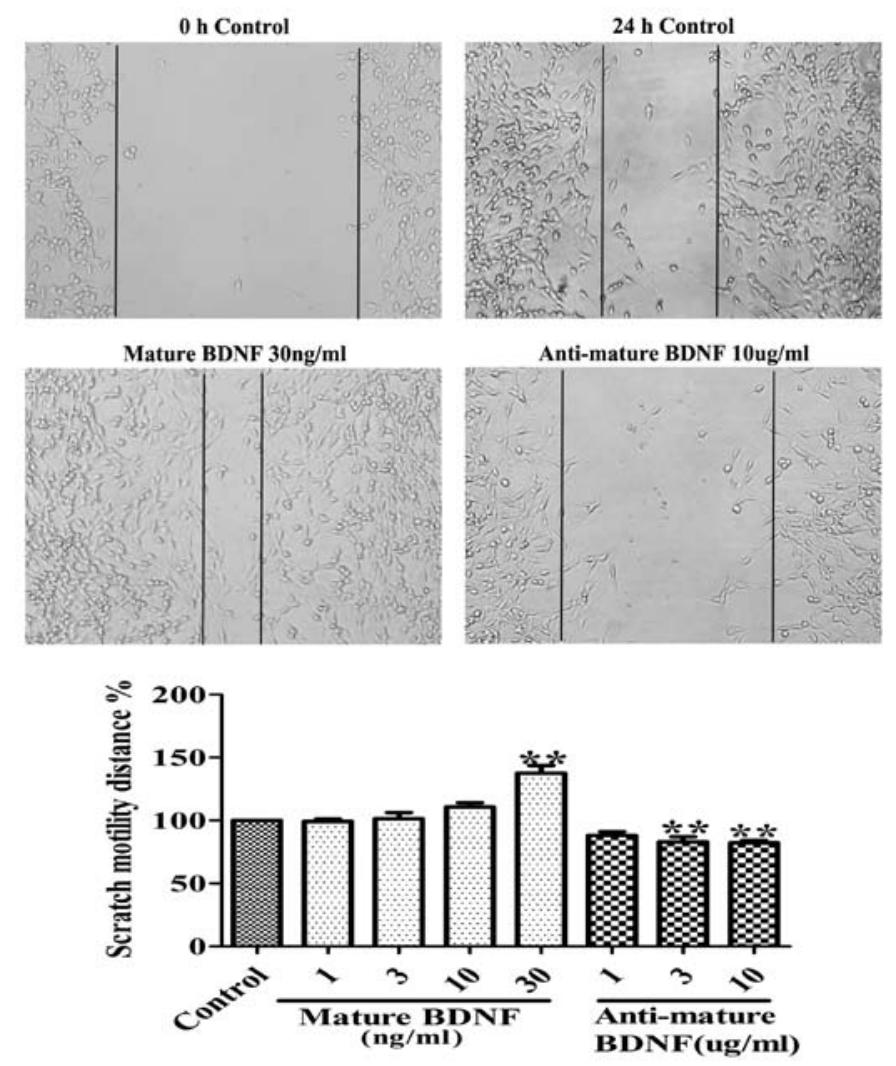

Figure 4. Effect of recombinant mature BDNF and anti-mature BDNF on cell motility of C6 glioma cells. A monolayer of cells was scratched with a 10- $\mu 1$ pipette tip. The cells were untreated $(0 \mathrm{~h})$ or treated with anti-mature BDNF $(10 \mu \mathrm{g} / \mathrm{ml})$ or recombinant mature BDNF protein $(30 \mathrm{ng} / \mathrm{ml})$ for $24 \mathrm{~h}$. The representative results were observed under a phase contrast microscope and photographed.
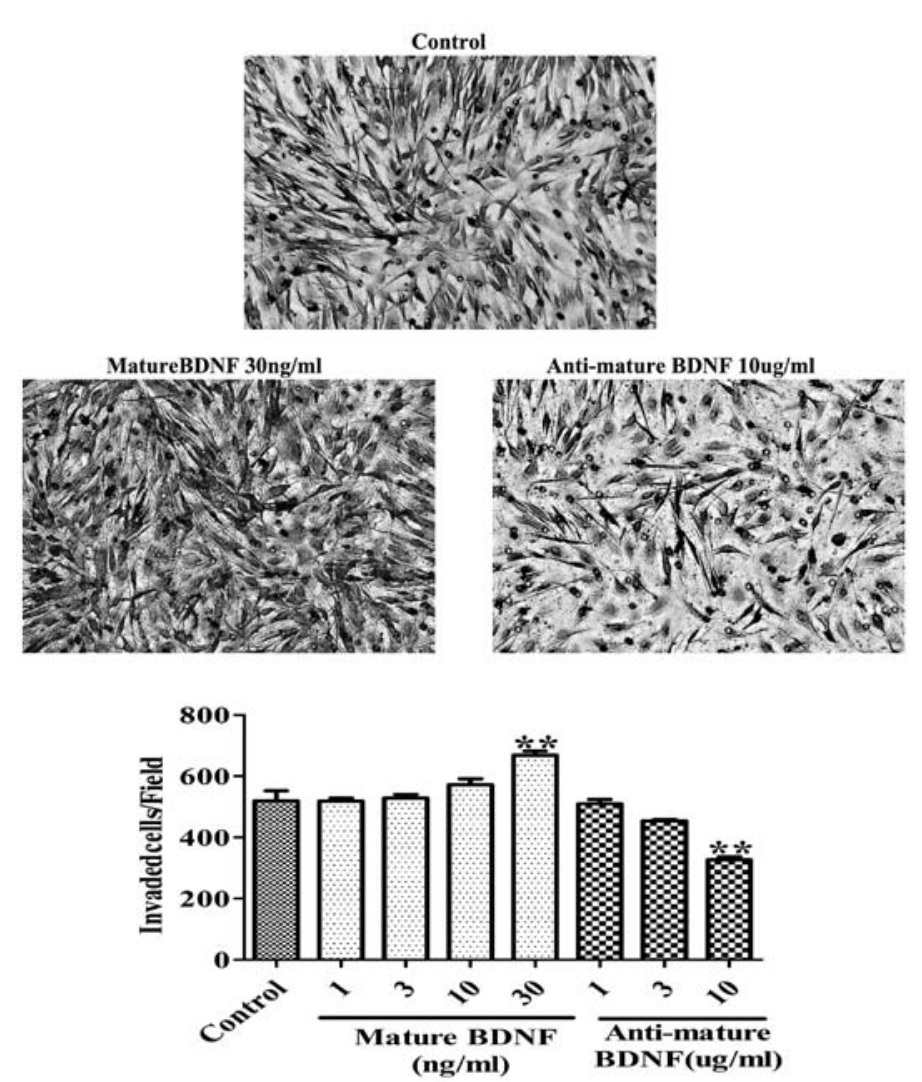

Figure 5. Effect of mature BDNF and anti-mature BDNF antibodies on C6 cell invasion. Photomicrographs of C6 cells that invaded through the Transwell membranes. Cells were treated with anti-mature BDNF antibodies $(10 \mu \mathrm{g} / \mathrm{ml})$, mature BDNF $(30 \mathrm{ng} / \mathrm{ml})$ or untreated for $24 \mathrm{~h}$. The number of cells on the bottom of the insert were counted by DAPI staining and were stained with Cresyl violet solution to confirm the DAPI staining data. Results were replicated in three independent experiments. Data were compared with the control group. ${ }^{* *} \mathrm{P}<0.01$. 
apoptosis was significantly decreased in a dose-dependent manner when C6 glioma cells were treated with mature BDNF $(1,3,10$ and $30 \mathrm{ng} / \mathrm{ml})$ in serum-free medium for $48 \mathrm{~h}$ (Fig. 3A, $\mathrm{C}$ and $\mathrm{E})$.

Mature BDNF increases motility and invasion of C6 glioma cells. Next, we investigated the effect of mature BDNF on motility and invasion by performing a scratch assay and a Boyden chamber assay on glioma cells. The scratch assay showed that the wound closure activity was increased in C6 glioma cells following treatment with mature BDNF. In contrast, anti-mature BDNF antibodies decreased the migratory activity after a 24-h culture (Fig. 4). Furthermore, the Boyden chamber assay revealed that cell invasion was significantly increased by mature BDNF (30 ng/ml; 28.65 $2.69 \%$; $\mathrm{P}<0.001$; Fig. 5) and was inhibited by anti-mature BDNF antibodies $(10 \mu \mathrm{g} / \mathrm{ml} ; 47.12 \pm 2.11 \%$; $\mathrm{P}<0.001$; Fig. 5). Moreover, exogenous BDNF stimulation increased cell invasion in a dose-dependent manner in vitro after $24 \mathrm{~h}$ of culture, whereas anti-mature BDNF antibodies decreased the activity in a dose-dependent manner (Fig. 5). These data demonstrate that mature BDNF plays a role in promoting motility and invasion of C6 glioma cells.

\section{Discussion}

ProBDNF and mature BDNF play opposing roles in neuronal function (6-8,17-21). Their diverse actions are mediated through two different transmembrane receptor signalling systems: p75NTR and TrkB. ProBDNF is a high-affinity, functional ligand for the pro-apoptotic p75NTR, whereas the proteolytically cleaved mature BDNF is the preferred ligand for TrkB. The important roles of the BDNF/TrkB signalling system in tumour cell proliferation and survival have been demonstrated (22-25). Previous studies have demonstrated that TrkB frequently exhibits robust expression in highly invasive tumours (11) and is a key regulator of tumour malignancy $(26,27)$. BDNF has also been found to be expressed in a series of tumours, including tumors in the CNS (28) and enhances tumour cell survival and resistance to chemotherapy (29). However, few studies were able to distinguish mature BDNF from proBDNF due to the limitation of specific antibodies. Recent studies have shown that proBDNF is a potent tumour suppressor $(13,14)$. We previously generated specific antibodies to mature BDNF and proBDNF, respectively. Our present study demonstrated that proBDNF negatively regulates the growth and migration of glioma cells through p75NTR (13).

In the present study, we found that mature BDNF and its receptor TrkB are highly expressed by glioma cells. Using the C6 glioma cell model, we found that exogenous recombinant mature BDNF increased growth and decreased apoptosis. Anti-mature BDNF treatment decreased proliferation and increased the apoptosis of C6 glioma cells in a dose-dependent pattern, indicating the ability of endogenous mature BDNF to promote cell proliferation and survival. BDNF/TrkB signalling is a key pathway which regulates infiltration of malignant tumours (30). High-grade glioma is notorious for its invasiveness and rapid penetration to normal tissues (31). Our results also indicate that mature BDNF promotes C6 cell infiltration and migration in a dose-dependent manner. These findings suggest that mature BDNF contributes to glioma growth and migration and may be a potential prognostic marker in glioma. Suppression of the mature BDNF/TrkB signalling pathway by either mature BDNF neutralising antibodies or TrkB-receptor antibodies may have therapeutic significance in high-grade glioma.

The ratio of proBDNF to mature BDNF levels was found to be decreased in high grade glioma tissues and was negatively correlated with tumour grade (13). In the present study, mature BDNF promoted glioma cell growth in vitro. Therefore, it is likely that increased levels of mature BDNF contribute mainly to tumourigenesis, as observed in previous reports. Both proBDNF and mature BDNF are present in gliomas. These findings suggest that the proBDNF-p75-sortilin pathway may be a balancing signal to tumour growth by the mature BDNF-TrkB pathway. The balance between tumour cell survival and death could depend upon the proportions of mature and proBDNF available to cells expressing TrkB and p75NTR.

Given the opposing functions of proBDNF and mature BDNF in glioma, it would be of great interest to study the precise mechanisms controlling the relative expression levels of proBDNF and mature BDNF to limit or amplify distinct neurotrophin activities in the development of glioma.

In conclusion, using C6 cells as a model, we demonstrated that mature BDNF induces tumour cell proliferation and invasion in vitro. Our observations provide the framework for novel therapeutic strategies through targeting mature BDNF/TrkB signalling cascades in glioma.

\section{Acknowledgements}

The present study was supported by grants to X.F.Z. from the Chinese MST 2011CB944200 and Australian NHMRC (595937); and to Z.C.X. from the Talent Program, Yunnan, China and the Monash Professorial Fellowship. We wish to thank Ms Kate Rees from UniSA for her critical reading of the manuscript.

\section{References}

1. Barde YA: Trophic factors and neuronal survival. Neuron 2: 1525-1534, 1989.

2. Bartkowska K, Turlejski K and Djavadian RL: Neurotrophins and their receptors in early development of the mammalian nervous system. Acta Neurobiol Exp 70: 454-467, 2010.

3. Zhou XF, Song XY, Zhong JH, Barati S, Zhou FH and Johnson SM: Distribution and localization of pro-brain-derived neurotrophic factor-like immunoreactivity in the peripheral and central nervous system of the adult rat. J Neurochem 91: 704-715, 2004.

4. Seidah NG and Chretien M: Proprotein and prohormone convertases: a family of subtilases generating diverse bioactive polypeptides. Brain Res 848: 45-62, 1999.

5. Barker PA: Whither proBDNF? Nat Neurosci 12: 105-106, 2009.

6. Teng HK, Teng KK, Lee R, Wright S, Tevar S, Almeida RD, Kermani P, Torkin R, Chen ZY, Lee FS, Kraemer RT, Nykjaer A and Hempstead BL: ProBDNF induces neuronal apoptosis via activation of a receptor complex of p75NTR and sortilin. J Neurosci 25: 5455-5463, 2005.

7. Kenchappa RS, Zampieri N, Chao MV, Barker PA, Teng HK, Hempstead BL and Carter BD: Ligand-dependent cleavage of the P75 neurotrophin receptor is necessary for NRIF nuclear translocation and apoptosis in sympathetic neurons. Neuron 50: 219-232, 2006. 
8. Fan YJ, Wu LL, Li HY, Wang YJ and Zhou XF: Differential effects of pro-BDNF on sensory neurons after sciatic nerve transection in neonatal rats. Eur J Neurosci 27: 2380-2390, 2008

9. Desmet CJ and Peeper DS: The neurotrophic receptor TrkB: a drug target in anti-cancer therapy? Cell Mol Life Sci 63: 755-759, 2006.

10. Hamel W, Westphal M, Szonyi E, Escandon E and Nikolics K: Neurotrophin gene expression by cell lines derived from human gliomas. J Neurosci Res 34: 147-157, 1993.

11. Assimakopoulou M, Kondyli M, Gatzounis G, Maraziotis T and Varakis J: Neurotrophin receptors expression and JNK pathway activation in human astrocy tomas. BMC Cancer 7: 202, 2007.

12. Aronica E, Leenstra S, Jansen GH, van Veelen CW, Yankaya B and Troost D: Expression of brain-derived neurotrophic factor and tyrosine kinase B receptor proteins in glioneuronal tumors from patients with intractable epilepsy: colocalization with N-methyl-D-aspartic acid receptor. Acta Neuropathol 101: 383-392, 2001.

13. Xiong J, Zhou L, Yang M, Lim Y, Zhu YH, Fu DL, Li ZW, Zhong JH, Xiao ZC and Zhou XF: ProBDNF and its receptors are upregulated in glioma and inhibit the growth of glioma cells in vitro. Neuro Oncol 15: 990-1007, 2013.

14. Akil H, Perraud A, Melin C, Jauberteau MO and Mathonnet M: Fine-tuning roles of endogenous brain-derived neurotrophic factor, TrkB and sortilin in colorectal cancer cell survival. PloS One 6: e25097, 2011.

15. Kelly KJ, Sandoval RM, Dunn KW, Molitoris BA and Dagher PC: A novel method to determine specificity and sensitivity of the TUNEL reaction in the quantitation of apoptosis. Am J Physiol Cell Physiol 284: C1309-C1318, 2003.

16. Xu ZQ, Sun Y, Li HY, Lim Y, Zhong JH and Zhou XF: Endogenous proBDNF is a negative regulator of migration of cerebellar granule cells in neonatal mice. Eur J Neurosci 33 $1376-1384,2011$.

17. Woo NH, Teng HK, Siao CJ, Chiaruttini C, Pang PT, Milner TA, Hempstead BL and Lu B: Activation of p75NTR by proBDNF facilitates hippocampal long-term depression. Nat Neurosci 8 : 1069-1077, 2005

18. Lu B: Pro-region of neurotrophins: role in synaptic modulation. Neuron 39: 735-738, 2003.

19. Lu B, Pang PT and Woo NH: The yin and yang of neurotrophin action. Nat Rev Neurosci 6: 603-614, 2005.

20. Koshimizu H, Hazama S, Hara T, Ogura A and Kojima M: Distinct signaling pathways of precursor BDNF and mature BDNF in cultured cerebellar granule neurons. Neurosci Lett 473: 229-232, 2010.
21. Sun Y, Lim Y, Li F, Liu S, Lu JJ, Haberberger R, Zhong JH and Zhou XF: ProBDNF collapses neurite outgrowth of primary neurons by activating RhoA. PLoS One 7: e35883, 2012.

22. Huang YT, Lai PC, Wu CC, Hsu SH, Cheng CC, Lan YF and Chiu TH: BDNF mediated TrkB activation is a survival signal for transitional cell carcinoma cells. Int J Oncol 36: 1469-1476, 2010.

23. Lam CT, Yang ZF, Lau CK, Tam KH, Fan ST and Poon RT: Brain-derived neurotrophic factor promotes tumorigenesis via induction of neovascularization: implication in hepatocellular carcinoma. Clin Cancer Res 17: 3123-3133, 2011.

24. Pearse RN, Swendeman SL, Li Y, Rafii D and Hempstead BL: A neurotrophin axis in myeloma: TrkB and BDNF promote tumorcell survival. Blood 105: 4429-4436, 2005.

25. Thiele CJ, Li Z and McKee AE: On Trk - the TrkB signal transduction pathway is an increasingly important target in cancer biology. Clin Cancer Res 15: 5962-5967, 2009.

26. Haapasalo A, Sipola I, Larsson K, Akerman KE, Stoilov P, Stamm S, Wong G and Castren E: Regulation of TRKB surface expression by brain-derived neurotrophic factor and truncated TRKB isoforms. J Biol Chem 277: 43160-43167, 2002.

27. Haapasalo A, Saarelainen T, Moshnyakov M, Arumae U, Kiema TR, Saarma M, Wong G and Castren E: Expression of the naturally occurring truncated trkB neurotrophin receptor induces outgrowth of filopodia and processes in neuroblastoma cells. Oncogene 18: 1285-1296, 1999.

28. Edsjo A, Lavenius E, Nilsson H, Hoehner JC, Simonsson P, Culp LA, Martinsson T, Larsson C and Pahlman S: Expression of trkB in human neuroblastoma in relation to MYCN expression and retinoic acid treatment. Lab Invest 83: 813-823, 2003.

29. Ho R, Eggert A, Hishiki T, Minturn JE, Ikegaki N, Foster P, Camoratto AM, Evans AE and Brodeur GM: Resistance to chemotherapy mediated by TrkB in neuroblastomas. Cancer Res 62: 6462-6466, 2002.

30. Han L, Zhang Z, Qin W and Sun W: Neurotrophic receptor TrkB: is it a predictor of poor prognosis for carcinoma patients? Med Hypotheses 68: 407-409, 2007.

31. Goebell E, Paustenbach S, Vaeterlein O, Ding XQ, Heese O, Fiehler J, Kucinski T, Hagel C, Westphal $M$ and Zeumer H: Low-grade and anaplastic gliomas: differences in architecture evaluated with diffusion-tensor MR imaging. Radiology 239: 217-222, 2006. 